\title{
Facultative oligohaline habitat use in a mobile fish inferred from scale chemistry
}

\author{
M. E. Seeley ${ }^{1}$, B. D. Walther ${ }^{2, *}$ \\ ${ }^{1}$ University of Texas at Austin, Marine Science Institute, Port Aransas, Texas 78373, USA \\ ${ }^{2}$ Texas A\&M University-Corpus Christi, Corpus Christi, Texas 78412, USA
}

\begin{abstract}
Reconstructing fish movements is critical to understand the diversity of habitats required to sustain mobile species. Chemical constituents in otoliths have been invaluable for the field of fish migration ecology to track natal origins and reconstruct lifetime movement patterns. However, alternative non-lethal structures, such as scales, are preferred for imperiled species to avoid mortality. We analyzed 29 individual scales from highly migratory and vulnerable Atlantic tarpon Megalops atlanticus (hereafter referred to as tarpon) in the Gulf of Mexico to identify migrations across salinity gradients and associated trophic shifts using paired measurements of elemental $(\mathrm{Sr} / \mathrm{Ca})$ and isotopic $\left(\delta^{13} \mathrm{C}\right.$ and $\left.\delta^{15} \mathrm{~N}\right)$ proxies. Although tarpon can inhabit freshwater, the specific patterns of facultative oligohaline habitat use are unknown. Individual scale-based salinity and diet histories were highly variable, with 4 contingents identified depending on the presence and sequence of movements. Scale salinity proxies $\left(\mathrm{Sr} / \mathrm{Ca}\right.$ and $\delta^{13} \mathrm{C}$ ) indicated that tarpon spent on average $42 \pm 34 \%$ of their scale-based life histories within oligohaline habitats. Transhaline movements were accompanied by shifts in $\delta^{15} \mathrm{~N}$ that indicated putative trophic shifts between marine or estuarine and oligohaline food webs. Oligohaline habitat use is common yet individually facultative for tarpon. This information is critical to devise sustainable fisheries management plans that account for the full range of diverse habitats used by this species throughout its life. Chemical analyses of scales have the potential to be broadly informative about migrations and trophic interactions in species where lethal methods must be avoided.
\end{abstract}

KEY WORDS: Migration $\cdot$ Scales $\cdot$ Elements $\cdot$ Stable isotopes $\cdot$ Megalops atlanticus $\cdot$ Contingents

\section{INTRODUCTION}

'There is considerable movement in and out of streams by these fishes. If there is any regularity to it we have not been able to determine such.'

Breder (1944), p. 233

Migration allows species to increase fitness by seeking out optimal environments for growth and reproduction at different life history stages (Dingle \& Drake 2007). While migratory movements can be obligate, a growing number of species are now recognized to have subgroups, or contingents, that display distinct migratory behaviors. This diversity includes partial migration, wherein one contingent displays

${ }^{*}$ Corresponding author: benjamin.walther@tamucc.edu

${ }^{\S}$ Advance View was available online September 5, 2017 migratory behavior while another contingent is resident (Chapman et al. 2011, 2012) and differential migration, wherein migratory behaviors diverge among life history stages or sexes (Terrill \& Able 1988). These contingents themselves may be obligate or facultative. Such intraspecific diversity in migratory behavior may confer resilience to the population in the face of environmental variability (Secor 1999, Kerr et al. 2010). As a result, species with intraspecific migratory diversity may respond differently to altered fitness landscapes induced by human activities, including habitat loss, altered environmental conditions, and fisheries harvest. Further, quantifying whether and to what extent facultative migrations in predators

(C) The authors 2018. Open Access under Creative Commons by Attribution Licence. Use, distribution and reproduction are unrestricted. Authors and original publication must be credited. 
occur is an important step towards understanding the relative impact of transient predators to local food webs (Bond et al. 2015). In addition, understanding variable habitat use by highly migratory fishes is an essential prerequisite for effective spatially explicit management and conservation (Hobson 1999). However, the degree to which movements are obligate or facultative and the specific patterns of habitat use for many mobile taxa are unknown.

There are a range of potential tools available to characterize movement and habitat use in mobile fishes, each of which has inherent advantages and limitations. Acoustic and satellite tagging have the potential to reveal high-resolution information about movements and environmental parameters experienced by the individual; however, tag size, receiver array coverage, and battery life limit the life history stages with which tags can be used and the duration and spatial extent of collected data (Bégout et al. 2016, Schaefer \& Fuller 2016). In recent decades, the use of otolith chemistry has grown as a powerful method that can provide lifelong records of environmental and habitat use histories, particularly for fishes that traverse significant chemical gradients, such as diadromous taxa (Campana \& Thorrold 2001, Elsdon et al. 2008, Walther \& Limburg 2012). An inevitable disadvantage of otolith analysis is lethal sampling, which renders it unsuitable for use with imperiled species where mortality must be minimized or avoided completely. For this reason, interest in the use of non-lethal otolith 'analogues' has grown considerably in recent years.

Researchers have capitalized on both stable isotope ratios and elemental markers in fish scales to reconstruct diet and habitat histories in a wide range of taxa (Seeley et al. 2015, Tzadik et al. 2017). Scales share many properties with otoliths that allow them to be used as a non-lethal analogue. Both structures have incremental growth and incorporate chemical constituents from the surrounding environment and diet (Wells et al. 2000, Holá et al. 2011). Scales have a bipartite architecture composed of an external layer underlain by a basal plate. The external layer is well calcified and can be assayed for proxies such as $\mathrm{Sr} / \mathrm{Ca}$, while the basal plate is a hydroxyapatite matrix that can be assayed for stable isotope values such as $\delta^{13} \mathrm{C}$ and $\delta^{15} \mathrm{~N}$ (Seeley et al. 2015). Although both types of proxies can be successfully obtained from scales, few studies combine stable isotope and elemental assays due in part to size and architectural limitations that render it difficult to extract time series of both types of proxies from individual scales (Hutchinson \& Trueman 2006, Trueman \& Moore
2007). However, for species with sufficiently large scales that allow subsampling from interior scale increments and which are less subject to increment underplating that causes bias in isotope values, paired elemental and isotopic measurements across individual scales are possible (Woodcock \& Walther 2014).

We applied paired assays of stable isotope ratios and elemental values in scales to infer migratory movements and dietary histories of Atlantic tarpon Megalops atlanticus (hereafter referred to as tarpon). Tarpon are highly migratory euryhaline predators that inhabit subtropical to tropical waters throughout the Atlantic Ocean (Ault et al. 2008). Their ability to tolerate a wide range of salinities, temperatures, and dissolved oxygen concentrations allow them to occupy diverse coastal, estuarine, and freshwater habitats over the course of their lives (Harrington 1958, Crabtree et al. 1995, Luo et al. 2008). Tarpon are generalist feeders, and juveniles inhabiting coastal, estuarine, and riverine habitats consume diverse prey items, including copepods, fishes, and terrestrial insects (Jud et al. 2011). Tarpon are thought to inhabit estuarine and oligohaline habitats primarily during juvenile phases, although migrations into rivers have been observed in older individuals (Luo et al. 2008). The duration and frequency of migrations across these salinity gradients into oligohaline habitats at different life stages are not well known. Characterizing the degree of facultative use of oligohaline habitats is critical to devise effective management strategies that account for all required habitats that support different life history stages of tarpon, which are currently listed as 'Vulnerable' by the IUCN (Adams et al. 2014).

A few studies have investigated the ability of chemical proxies in structures such as otoliths to reveal tarpon migrations across salinity gradients (Brown \& Severin 2007, Rohtla \& Vetemaa 2016). However, because of their Vulnerable status, a nonlethal examination of scale chemistry is preferable to otoliths in this species. Tarpon scales are particularly suitable as an otolith analogue because their size (>6 cm diameter in mature fish) enables detailed chemical analyses (Harrington 1958). This size allows subsampling of interior increments for stable isotope values across scales as well as paired laser ablation analysis of the exterior calcified surface layer of the same scale. While discrete paired subsample analyses of tarpon scales have suggested individually diverse migratory and trophic interactions (Woodcock \& Walther 2014), a recently developed crosssectional laser ablation technique for obtaining con- 
tinuous elemental transects in these large scales allows more detailed assessments of migratory histories (Seeley et al. 2015). A paired analysis approach therefore allows putative dietary and migratory histories to be reconstructed for individual fish, providing significant insight into life history variability, facultative habitat use, and trophic interactions.

The aims of this study were to use isotopic and elemental signatures in tarpon scales to: (1) identify migratory contingents and lifetime patterns of oligohaline habitat use; and (2) assess whether movements across salinity gradients are accompanied by shifts in food web interactions. Together, these analyses provide novel insight into the migratory behavior and trophic structure of these imperiled fish.

\section{MATERIALS AND METHODS}

\section{Scale collection and preparation}

Tarpon scales were opportunistically collected along the Texas coast during fishing tournaments and from donations by local anglers. Scales were placed in water-resistant envelopes on which estimated length, weight, and capture location were recorded by anglers. From 2013 to 2015, scales were collected from 29 individual tarpon from 2 locations (Fig. 1). Collections occurred in Port Aransas ( $\mathrm{n}=7$, with 2 collected in 2013, 4 in 2014, and 1 in 2015), Matagorda Bay ( $\mathrm{n}=$ 22, with 9 in 2013 and 13 in 2014). Fish ranged from 0.91 to $90.72 \mathrm{~kg}$ and were considered sexually immature when $<18.2 \mathrm{~kg}$ ( $\mathrm{n}=$ 11) and sexually mature at $>18.2 \mathrm{~kg}(\mathrm{n}=18)$ (Crabtree et al. 1997, Ault \& Luo 2013). Scales were inspected under a microscope to ensure regular increments were present from the focus, or center of the scale, to the edge. Scales with disorganized interiors that lacked increments for a portion of scale growth were taken to be indicative of regenerated scales, and these were excluded from further analyses (Seeley et al. 2017).

Scale preparation for elemental analysis followed established methods. Methods for removing sequential subsamples for isotope analyses are detailed in Woodcock \& Walther (2014) and methods and diagrams detailing the cross-sectional laser ablation approach are described in Seeley et al. (2015). Methods and diagrams describing stable isotope subsampling and cross-sectioning for laser ablation are further elaborated on in Seeley et al. (2017). Briefly, a rectangle containing all increments from the focus to the edge of each scale was excised and embedded in epoxy. This rectangle was cross-sectioned to expose a smooth plane of the surficial calcified external layer, which was targeted for laser ablation inductively coupled plasma mass spectrometry (ICP-MS). Thus, continuous ICP-MS transects from focus to edge in the surficial calcified external layer were obtained for each scale. In addition, subsamples $0.5-2.0 \mathrm{mg}$ in mass were removed from the focus to the edge of each scale from an alternative transect offset radially approximately $90^{\circ}$ from the rectangle removed for ICPMS analyses. Dimensions of subsamples were chosen to obtain sufficient material per subsample for reliable analyses on an isotope ratio mass spectrometer. A total of 2-10 subsamples were removed per scale depending on scale diameter. Samples were spaced regularly across increments unless laser ablation elemental analyses indicated a major transition in Sr/Ca values occurred at a known location on the scale. Where such major elemental transitions were identified, scale subsamples were chosen to bracket the elemental shift to determine whether isotope shifts were concurrent. Each of these subsamples was analyzed separately with isotope ratio mass spectrometry (IRMS) to obtain individual time series of $\delta^{13} \mathrm{C}$ and $\delta^{15} \mathrm{~N}$ values that corresponded to the same time series obtained for elemental ratios via ICP-MS for each scale.

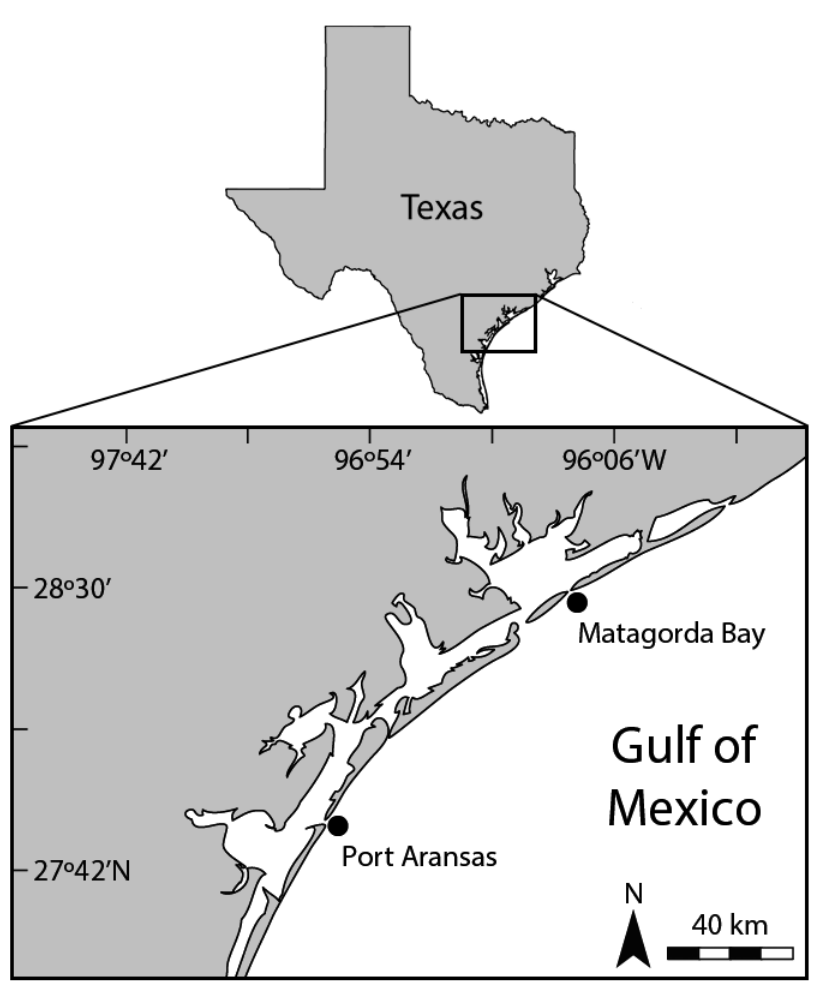

Fig. 1. Collection locations where scales were removed from wild tarpon (Matagorda Bay and Port Aransas) 


\section{Elemental analyses}

Scale analyses using ICP-MS were conducted at the Jackson School of Geosciences at the University of Texas with a New Wave Research UP193-FX fast excimer 193-nm-wavelength laser system coupled to an Agilent 7500 ce ICP-MS to quantify ${ }^{43} \mathrm{Ca}$ and ${ }^{88} \mathrm{Sr}$. Preablation was conducted on all samples to remove any potential surface contaminants. Scales were ablated from the focus to edge within the calcified external layer following the methods outlined by Seeley et al. (2015). The laser ablation speed was $25 \mu \mathrm{m} \mathrm{s}{ }^{-1}$, the laser spot diameter was $25 \mu \mathrm{m}$, the power was $30 \%$, and the repetition rate was $10 \mathrm{~Hz}$. The laser spot diameter was chosen so that transects from focus to edge could be completely contained within the exterior calcified layer of cross-sectioned scales. Laser energy densities (fluences) obtained for the analytical session ranged from 2.5 to $3.25 \mathrm{~J} \mathrm{~cm}^{-2}$. Certified reference materials NIST 612, NIST 610, and MAPS4 bracketed scale runs, while ${ }^{43} \mathrm{Ca}$ was used as an internal standard assuming a concentration of $39.89 \% \mathrm{Ca}$ in the sampled outer calcium phosphate layer, corresponding to an assumed composition of $\mathrm{Ca}_{10}\left(\mathrm{PO}_{4}\right)_{6}(\mathrm{OH})_{2}$. Analyses took place over 2 sessions in 2015. In spring 2015, the percent residual standard deviations (RSDs) for Sr were $2.13 \%$ and $2.32 \%$ for NIST 612 and 610 against MAPS4, respectively. In fall 2015, the RSDs for Sr were $4.51 \%$ and $6.67 \%$ for NIST 612 and 610 against MAPS4, respectively.

Occasionally, high magnitude Sr counts were observed on individual transects. These points occurred because the laser spot drifted out of the external layer and into the epoxy, or due to major cracks in the scale. Laser transect misplacement and cracks in the scale were confirmed visually by microscope subsequent to analytical sessions, and where confirmed, these sections of the elemental transects were removed and data were linearly interpolated to replace these missing portions of individual transects.

\section{Stable isotope analyses}

Analyses of $\delta^{13} \mathrm{C}$ and $\delta^{15} \mathrm{~N}$ values from scale subsamples were conducted twice in 2015. Each subsample was encapsulated in tin and analyzed at the University of California, Davis, Stable Isotope Facility using a PDZ Europa ANCA-GSL elemental analyzer interfaced to a PDZ Europa 20-20 isotope ratio mass spectrometer (Sercon). In the first sampling, samples were run against 4 reference materials (nylon: $\delta^{15} \mathrm{~N}=$ $-10.31 \%$, $\delta^{13} \mathrm{C}=-27.72 \%$; bovine liver: $\delta^{15} \mathrm{~N}=7.72 \%$, $\delta^{13} \mathrm{C}=-21.69 \%$; glutamic acid (USGS-41): $\delta^{15} \mathrm{~N}=$ $47.6 \%$, $\delta^{13} \mathrm{C}=37.63 \%$; and glutamic acid: $\mathrm{N}=9.52 \%$, $\delta^{15} \mathrm{~N}=-6.8 \%$, $\mathrm{C}=40.81 \%, \delta^{13} \mathrm{C}=-16.65 \%$ ). In the second sampling, samples were run against 4 reference materials (nylon: $\delta^{15} \mathrm{~N}=-10.31 \%, \quad \delta^{13} \mathrm{C}=$ $-27.72 \%$; bovine liver: $\delta^{15} \mathrm{~N}=7.72 \%$, $\delta^{13} \mathrm{C}=-21.69 \%$; glutamic acid: $\mathrm{N}=9.52 \%, \delta^{15} \mathrm{~N}=-6.8 \%$, $\mathrm{C}=40.81 \%$, $\delta^{13} \mathrm{C}=-16.65 \%$; and enriched alanine: $\delta^{15} \mathrm{~N}=$ $41.13 \%$, $\delta^{13} \mathrm{C}=43.02 \%$ o). Scales were not decalcified prior to analysis as previous investigations found no significant effect of decalcification on isotope values in tarpon scales (Woodcock \& Walther 2014).

\section{Oligohaline threshold estimation}

The proportion of dissolved ambient elemental concentrations in water that are taken up and incorporated into scales is defined by the partition coefficient $D$, calculated as $D_{\mathrm{Sr} / \mathrm{Ca}}=\left[(\mathrm{Sr} / \mathrm{Ca})_{\text {scale }}\right] /\left[(\mathrm{Sr} / \mathrm{Ca})_{\text {water }}\right]$ (Morse \& Bender 1990). The $D_{\mathrm{Sr} / \mathrm{Ca}}$ can be used to estimate expected scale Sr/Ca values in oligohaline waters given measured Sr/Ca water values. To calculate the $D_{\mathrm{Sr} / \mathrm{Ca}}$, the exterior portion (last $1000 \mu \mathrm{m}$ ) of Sr/Ca transects in scales from the 22 fish captured in marine environments was averaged to represent expected scale Sr/Ca values in marine habitats and parameterize the numerator of the $D_{\mathrm{Sr} / \mathrm{Ca}}$ equation. Scales from fish captured in estuarine habitats or scales containing a major shift in Sr/Ca values within the exterior $1000 \mu \mathrm{m}$ of their transects were excluded from this calculation. The denominator of the $D_{\mathrm{Sr} / \mathrm{Ca}}$ equation was parameterized with the globally homogeneous $\mathrm{Sr} / \mathrm{Ca}$ value of $8.54 \mathrm{mmol} \mathrm{mol}^{-1}$ (de Villiers 1999). This value is stable in marine waters worldwide due to the large reservoir and long residence time (2-5 million yr) of Sr in the ocean (Banner 2004), and therefore a robust value to use as a marine endmember.

Mean values of $\mathrm{Sr} / \mathrm{Ca}$ in the oligohaline (salinities of 0-5) portions of coastal streams and rivers in Texas have been analyzed by Walther \& Nims (2015) and were used here to develop a threshold for expected scale Sr/Ca values for tarpon inhabiting oligohaline waters. Water Sr/Ca values reported by Walther \& Nims (2015) were averaged, excluding reported values from water samples with salinities $>5$. This mean oligohaline endmember value was multiplied by the $D_{\text {Sr/Ca }}$ obtained above to calculate the expected scale Sr/Ca threshold value below which oligohaline residence was inferred, and is hereafter used as the mean threshold. To assess the robustness of this threshold to variations in the oligohaline endmember, a high threshold and a low threshold were calcu- 
lated using the mean \pm 1 SD of oligohaline Sr/Ca values reported by Walther \& Nims (2015).

\section{Statistics}

Pair-wise comparisons between all 3 proxies $\left(\delta^{13} \mathrm{C}\right.$, $\delta^{15} \mathrm{~N}$, and $\mathrm{Sr} / \mathrm{Ca}$ ) were made to determine whether proxies co-varied in scales. Because $\mathrm{Sr} / \mathrm{Ca}$ transects were continuous while isotope analyses were discrete, portions of each $\mathrm{Sr} / \mathrm{Ca}$ transect covering the area encompassed by the isotope subsamples were averaged to obtain discrete $\mathrm{Sr} / \mathrm{Ca}$ values that corresponded to comparable growth regions for each isotope subsample to allow pair-wise comparisons.

While some scales had up to 10 subsamples covering large ranges in elemental and isotope values, others had limited subsamples due to small-scale diameters and restricted proxy value ranges. Therefore, the effect of pooling multiple scales together was investigated. Pair-wise comparisons among proxies $\left(\delta^{13} \mathrm{C}\right.$ vs. $\delta^{15} \mathrm{~N}, \mathrm{Sr} / \mathrm{Ca}$ vs. $\delta^{13} \mathrm{C}$, and $\mathrm{Sr} / \mathrm{Ca}$ vs. $\delta^{15} \mathrm{~N}$ ) were calculated, and 5 different scales with multiple subsamples and large proxy value ranges were selected to be used as individuals while the remaining 24 scales were pooled into a sixth 'mega-individual'. Analyses of covariance (ANCOVAs) were calculated for these 6 groups (5 individuals and 1 'mega-individual') and there were no significant differences in the interactions or slopes for $\mathrm{Sr} / \mathrm{Ca}$ or $\delta^{13} \mathrm{C}$ using either $\delta^{13} \mathrm{C}$ or $\delta^{15} \mathrm{~N}$ ( $\mathrm{p}>0.05$ for all) as a covariate. This comparison indicated that the relationships among proxies for the pooled 'mega-individual' were similar to individuals with robust subsample replication, thus justifying pooling subsamples among all scales for regression analyses. After pooling all subsamples together across all scales $(\mathrm{n}=29)$, least squares linear regressions were then performed between $\delta^{15} \mathrm{~N}$ and $\delta^{13} \mathrm{C}$, $\delta^{13} \mathrm{C}$ and $\mathrm{Sr} / \mathrm{Ca}$, and $\delta^{15} \mathrm{~N}$ and $\mathrm{Sr} / \mathrm{Ca}$ to determine relationships between the chemical tracers.

The proportion of continuous scale $\mathrm{Sr} / \mathrm{Ca}$ transects spent below the thresholds, indicating oligohaline residence, were calculated for all fish in aggregate as well as separately for immature and mature tarpon. Significant shifts in scale Sr/Ca values across scale transects were identified by a regime-shift detection algorithm (Rodionov 2004). The algorithm was set with a 0.05 significance level, a minimum regime length of 1000 cells or approximately $5000 \mu \mathrm{m}$, and a Huber's weight parameter of 1 . When adjacent points differed significantly based on the minimum specified regime length and predetermined significance level, a shift was identified and a new moving aver- age was applied until the next shift occurred. Once the algorithm identified all shifts in a transect, mean values between shifts (regimes) were calculated. Each regime value was then compared with the calculated oligohaline thresholds to determine whether the regime was within oligohaline waters (at or below the threshold) or in meso-polyhaline waters (above the threshold). For the purposes of this study, meso-polyhaline water encompasses any salinity ranging from 5 to 30 regardless of being near shore, coastal, or offshore. The proportion of each transect spent below the threshold was then calculated for each scale. These calculations were made separately for each transect using the mean threshold as well as the high and low thresholds. Distributions of the individual shifts and transect proportions spent in oligohaline waters obtained based on the 3 different thresholds were compared to determine sensitivity of results to threshold selection.

Two metrics of shifts in $\delta^{13} \mathrm{C}$ and $\delta^{15} \mathrm{~N}$ values for each scale transect were calculated. First, the total range in isotope ratios across each scale was obtained by subtracting the minimum from the maximum isotope value observed in each scale. This range reflected the maximal difference between observed isotope values among all subsamples from an individual scale. Second, the edge-minus-focus values were calculated to determine overall lifetime shifts in values from squamation to capture. These 2 metrics were compared to determine whether edge-minusfocus values adequately captured the overall lifetime shifts in isotope values. If total ranges and edge-minus-focus values were identical, then the difference between focus and edge values fully captured the range of isotope values observed across the life of the fish. However, if total ranges exceeded focus-minusedge differences, this implied that an isotopic shift, perhaps reflective of mid-life migrations or diet shifts, occurred in the middle of the scale transect that exceeded lifetime ontogenetic shifts.

\section{RESULTS}

\section{Proxies, partition coefficients, and thresholds}

Least squares linear regressions yielded significant positive linear relationships $(\mathrm{p}<0.001)$ for $\delta^{15} \mathrm{~N}$ vs. $\delta^{13} \mathrm{C}, \delta^{13} \mathrm{C}$ vs. Sr/Ca, and $\delta^{15} \mathrm{~N}$ vs. Sr/Ca (Fig. 2). The calculated $\mathrm{Sr} / \mathrm{Ca}$ partition coefficient for all wild scales was $D_{\mathrm{Sr}}=0.27$. This value was then applied to the mean oligohaline water $\mathrm{Sr} / \mathrm{Ca}$ concentrations of (mean $\pm \mathrm{SD}$ ) $5.23 \pm 1.23 \mathrm{mmol} \mathrm{mol}^{-1}$ measured by 

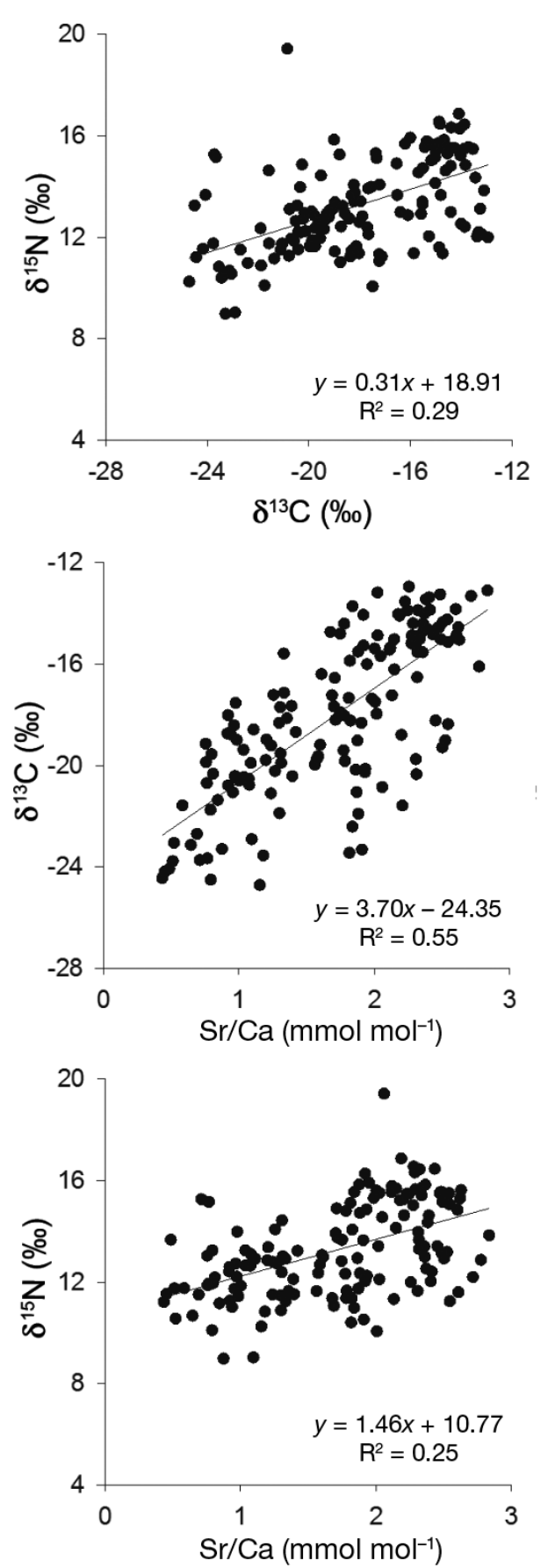

Fig. 2. Linear regressions showing the relationships between 3 chemical proxies in tarpon scales for salinity conditions $\left(\mathrm{Sr} / \mathrm{Ca}, \delta^{13} \mathrm{C}\right)$ and trophic dynamics $\left(\delta^{15} \mathrm{~N}\right)$. Scale subsamples from all wild fish were pooled for these regressions

Walther \& Nims (2015) to obtain scale Sr/Ca values corresponding to high, mean and low oligohaline thresholds in scales. Estimated Sr/Ca thresholds in scales were $1.7 \mathrm{mmol} \mathrm{mol}^{-1}$ (high threshold), $1.43 \mathrm{mmol}$ $\mathrm{mol}^{-1}$ (mean threshold), and $1.10 \mathrm{mmol} \mathrm{mol}^{-1}$ (low threshold).
Table 1. Mean \pm 1 SD proportions (\%) of individual tarpon scale transects below low, mean, and high scale Sr/Ca oligohaline threshold levels for all fish, mature fish only, and immature fish only. These values indicate proportions of transects that are considered time spent in oligohaline waters

\begin{tabular}{|lcccc|}
\hline \multirow{2}{*}{ Category } & \multirow{2}{*}{$\mathrm{N}$} & \multicolumn{3}{c|}{ Threshold } \\
\cline { 3 - 5 } & & Low & Mean & High \\
\hline All fish & 29 & $27 \pm 34$ & $42 \pm 34$ & $54 \pm 32$ \\
Mature & 18 & $15 \pm 21$ & $30 \pm 26$ & $42 \pm 26$ \\
Immature & 11 & $46 \pm 43$ & $63 \pm 38$ & $73 \pm 32$ \\
\hline
\end{tabular}

\section{Elemental shifts}

When considering all fish together, (mean \pm SD) $42 \pm 34 \%(\mathrm{n}=29)$ of scale transects were below the mean Sr/Ca oligohaline threshold. This indicated that many fish spent large portions of their lives in oligohaline waters, although there was considerable inter-individual variability in oligohaline use. When grouped by maturity and using the same mean oligohaline threshold, $30 \pm 26 \%$ of scale transects from mature fish and $63 \pm 38 \%$ of scale transects from immature fish were below the mean threshold, indicating that immature fish spent larger proportions of their lives in oligohaline waters. Oligohaline proportions based on high and low thresholds showed similar trends (Table 1), with immature fish spending higher proportions of their lives in oligohaline waters $(73 \pm 32 \%$ or $46 \pm$ $43 \%$ using the high or low threshold, respectively) than mature fish $(42 \pm 26 \%$ or $15 \pm 21 \%$ using the high or low threshold, respectively). Thus, although the absolute values differ, the trends in patterns of oligohaline habitat use are robust to the choice of thresholds examined here.

Examination of regime shifts within individual transects allowed classification of wild fish into 4 contingents based on the presence and sequence of movement into oligohaline waters as determined with the mean threshold. Fish were classified as nonmigrant marine $(\mathrm{n}=8)$, non-migrant oligohaline $(\mathrm{n}=$ $4)$, migrant oligohaline-marine $(\mathrm{n}=12)$, or migrant marine-oligohaline-marine $(\mathrm{n}=5)$ depending on whether fish moved into oligohaline waters and the sequence of movements (Fig. 3). Therefore, of the fish examined and excluding the non-migrant marine fish that never entered oligohaline waters, a remainder of $72 \%(n=21)$ made use of oligohaline habitats to some degree during their lifetimes (Fig. 4). These classifications were made regardless of the timing of movements, so movements into oligohaline waters were subsequently examined to deter- 

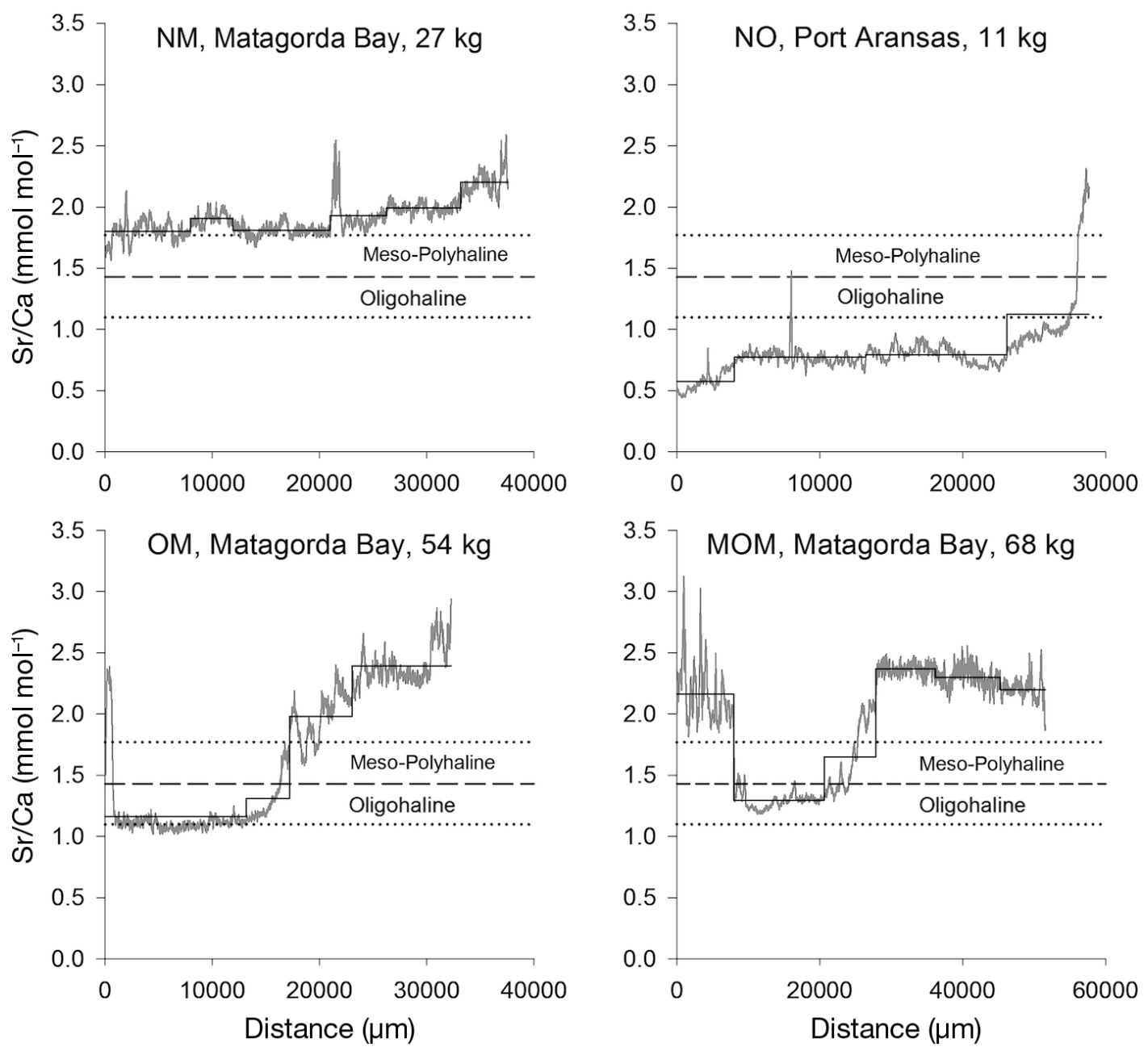

Fig. 3. Representative Sr/Ca scale transects of 4 wild fish (gray line) and major regime shifts (black line). The dashed line represents the mean oligohaline scale $\mathrm{Sr} / \mathrm{Ca}$ threshold and the dotted lines represent the high and low thresholds. Values below the threshold are considered residence in oligohaline waters, while values above the threshold are considered residence in mesopolyhaline waters. Fish were classified as non-migrant marine (NM), non-migrant oligohaline (NO), migrant oligohaline-marine $(\mathrm{OM})$, or migrant marine-oligohaline-marine (MOM). Capture locations and estimated fish mass are indicated over each transect

mine whether migratory shifts occurred early or late in the transect. Of the 17 fish whose $\mathrm{Sr} / \mathrm{Ca}$ scale transects crossed the mean oligohaline threshold at some point, 16 of them crossed the threshold in the first $75 \%$ of their scale transects, while only 1 fish had a significant shift in the last $25 \%$ of their scale transects (Fig. 5).

\section{Isotope shifts}

Total ranges and edge-minus-focus values for $\delta^{13} \mathrm{C}$ and $\delta^{15} \mathrm{~N}$ in wild fish were individually variable, although mean ranges and edge-minus-focus values were comparable for all fish and immature and mature fish considered separately (Table 2). Discrepancies between the 2 metrics were more pronounced

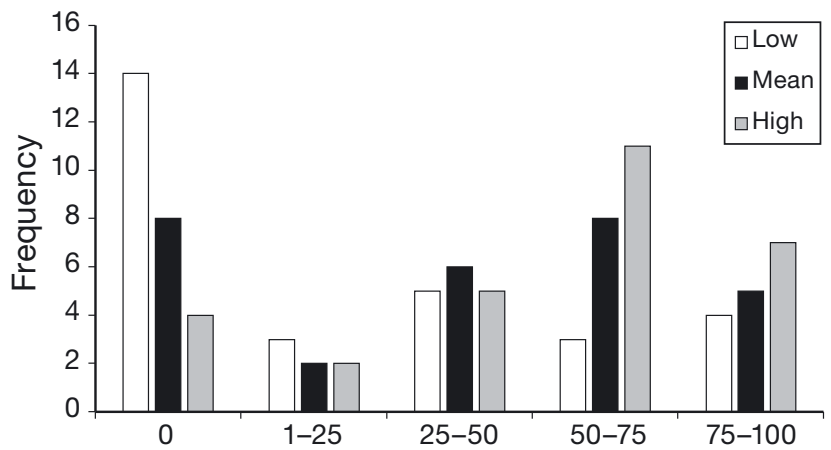

Proportion of transect below oligohaline threshold (\%)

Fig. 4. Frequency of wild tarpon binned according to the proportion of their Sr/Ca scale transect that fell below an oligohaline threshold. Fish whose transect never fell below a threshold are indicated separately $(0 \%)$. Histograms are shown for transects using low, mean, or high thresholds 


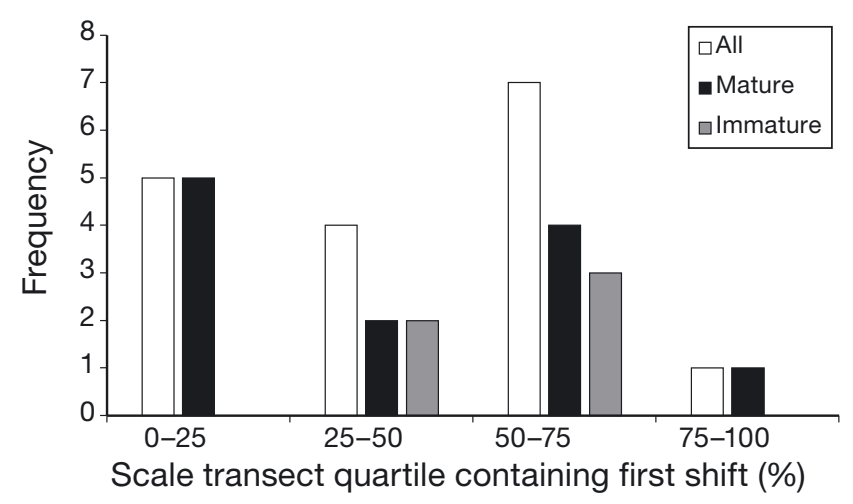

Fig. 5. Frequency of tarpon grouped according to whether their first significant shift in Sr/Ca across the mean oligohaline threshold occurred during the first, second, third, or fourth quartile of each transect. Fish whose transects never crossed the threshold are omitted. Histograms are shown for all fish pooled, and for mature and immature fish separately

for mature fish, where total ranges occasionally exceeded focus-minus-edge differences (Fig. 6). This situation occurred when an older fish had more opportunity to move between oligohaline and mesopolyhaline waters and therefore likely exceed the expected ontogenetic changes in isotope values due to a mid-life migratory movement or diet shift.

\section{DISCUSSION}

This study used paired isotopic and elemental proxies in scales to reveal a wide range of variability in movements across salinity gradients in a highly mobile predatory fish. Although tarpon are known to be tolerant of low-salinity waters, the prevalence and extent of oligohaline habitat use has rarely been assessed. We found a high degree of individual variability in movements into low-salinity waters, including fish that never cross the threshold into oligohaline habitats and others that make extensive use of those same habitats. While oligohaline residence was more likely to occur early in life, it was not exclu-

Table 2. Differences in $\delta^{15} \mathrm{~N}$ and $\delta^{13} \mathrm{C}$ values across tarpon scale transects. Mean $\pm \mathrm{SD}$ values are shown for differences between focus and edge subsamples (edge values minus focus values) and total range (maximum minus minimum values) for all fish, mature fish, and immature fish

\begin{tabular}{|lcccccc|}
\hline & \multirow{2}{*}{$\mathrm{N}$} & \multicolumn{2}{c}{$\delta^{15} \mathrm{~N}(\%)$} & & \multicolumn{2}{c|}{$\delta^{13} \mathrm{C}(\%)$} \\
\cline { 3 - 4 } \cline { 6 - 7 } & & Edge - focus & Total range & & Edge - focus & Total range \\
\hline All fish & 29 & $3.02 \pm 1.58$ & $3.34 \pm 1.59$ & & $3.54 \pm 2.26$ & $4.41 \pm 1.88$ \\
Mature & 18 & $3.08 \pm 1.09$ & $3.52 \pm 1.08$ & & $3.67 \pm 2.13$ & $4.82 \pm 1.17$ \\
Immature & 11 & $2.93 \pm 2.22$ & $3.04 \pm 2.22$ & & $3.32 \pm 2.56$ & $3.73 \pm 2.60$ \\
\hline
\end{tabular}
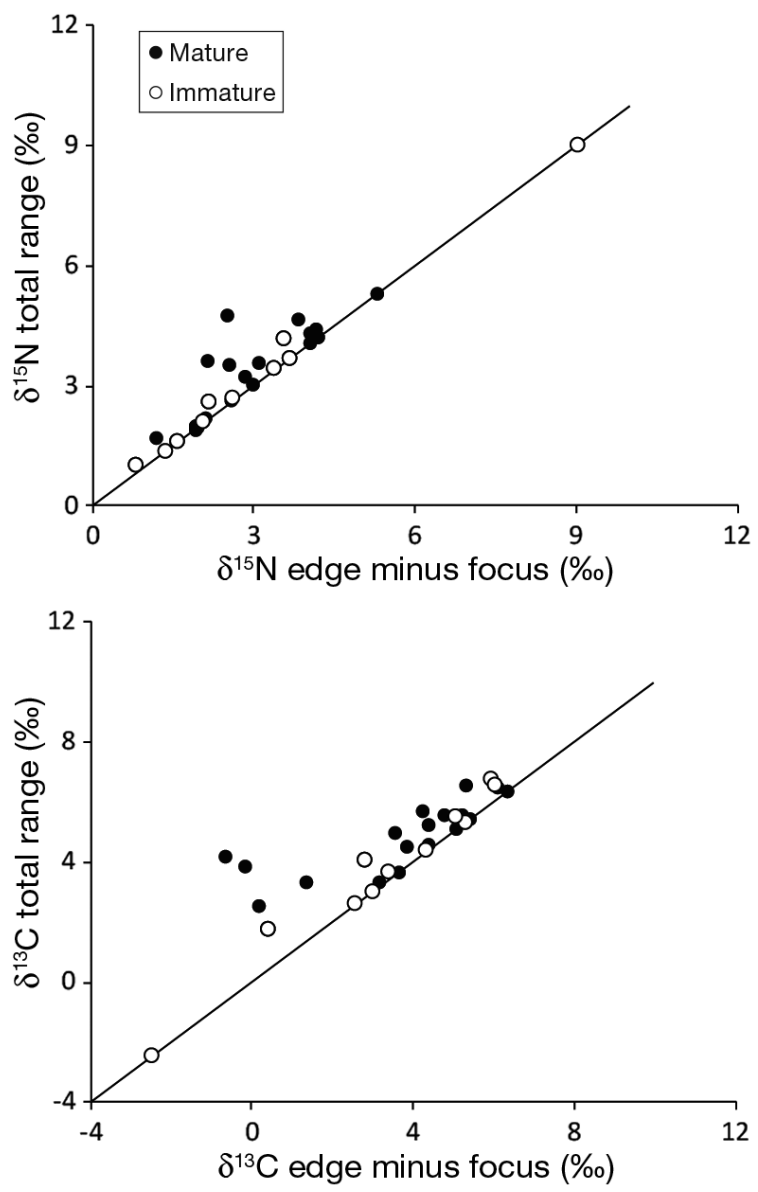

Fig. 6. Comparison between edge-minus-focus values and total range values of tarpon scale $\delta^{15} \mathrm{~N}$ and $\delta^{13} \mathrm{C}$ stable isotope values for immature (open symbols) and mature (closed symbols) fish. The 1:1 relationship is indicated by the solid line

sively restricted to the early portions of the scale transects, and could occur at any point along a transect. Currently, scale increments in tarpon have not been validated for aging purposes, so absolute ages could not be assigned to these transitions. However, scale growth proceeds with age throughout the life of the fish, and thus the position of oligohaline shifts across transects is at least broadly informative of variable timings of these movements. Finally, movements into oligohaline waters were accompanied by shifts in $\delta^{15} \mathrm{~N}$ ratios, indicating coincident shifts in food web interactions that suggested fish relied on freshwater and terrestrial energy sources during transitory movements. This study highlights the utility of non-lethal sampling and chemical assays of scales in a highly mobile and vulnerable species. 


\section{Scale chemistry as an otolith analogue}

The use of chemical markers in scales has a long history (reviewed by Seeley et al. 2015), although research on mobile fishes has been biased towards otolith analyses. This bias is largely due to architectural properties of otoliths that favor their use over other structures. Otoliths grow concentrically outward, meaning a sectioned plane can allow discrete sampling of specified growth regions with minimal mixing of subsequent increments using either probebased (e.g. laser ablation; Fowler et al. 1995) or extraction methods (e.g. micromilling; Dufour et al. 2008). Scale architecture is more complex, with a concentrically growing calcified surficial layer and a poorly calcified basal plate. A number of researchers have therefore used top-down ablations of the external layer, either targeting a particular growth region, such as the focus for nursery signatures (Wells et al. 2003, Flem et al. 2005) and the edge for information just prior to capture (Woodcock et al. 2013, Ramsay et al. 2015), or transects across entire scales (Clarke et al. 2007, Borcherding et al. 2008). Because scales in many species are highly rugose and vary significantly in thickness from focus to edge, a top-down probe transect approach can be difficult with the lack of a smooth surface for assays and the depth of focus changes across increments. For this reason, some researchers have employed a sagittal cross-sectional approach that exposes the external layer with a flat surface of uniform thickness preferable for probebased analyses (Courtemanche et al. 2006, Holá et al. 2011). Cross-sectioning is particularly important for elemental assays of tarpon scales, given their large size, high degree of surficial relief, and significant variation in thickness from focus to edge. We therefore developed a cross-sectional approach that allows continuous ablation from focus to edge and retains high-resolution information about life histories and potential migrations (Seeley et al. 2015).

In contrast to the external layer, growth of organic layers is not concentric, and new basal plates grow underneath previous layers (Trueman \& Moore 2007). As a result, subsamples of interior portions of scales assayed for isotope ratio values will contain a mixture of old and new basal plate material, while subsamples from the leading edge of the scale will contain primarily new material (Hutchinson \& Trueman 2006). This poses challenges for researchers seeking to reconstruct individual lifetime patterns of diet history because isotope ratio values from interior subsections will be biased towards values accreted later in life. As a result, many studies investigating stable isotope ratios in scales forego sequential subsampling of scales and simply analyze whole or pooled scales (Perga \& Gerdeaux 2003, Johnson \& Schindler 2012, Ramsay et al. 2012) or excise the most recent exterior region of scale growth to minimize underplating bias (MacKenzie et al. 2011, Cambiè et al. 2016). Although underplating occurs in all scales, the magnitude of resulting isotope bias depends on the relative thickness of recent underlying layers relative to older layers (Hutchinson \& Trueman 2006). In addition, fish that cross major salinity gradients (reflected in $\delta^{13} \mathrm{C}$ ) or switch between sufficiently different food webs or trophic positions (reflected in $\delta^{15} \mathrm{~N}$ ) may still result in detectable variation across increments that reflect movement and dietary histories despite underplating bias. Although the absolute magnitude of changes in isotope ratio values across increments may be averaged downwards due to underplating, patterns and timing of movements across isoscapes could still be resolved, and relative changes in isotope ratios can be considered a minimum estimate of endmember divergence.

The ability to assay elemental proxies for salinity, such as Sr/Ca in the external layer, which should not be subject to underplating bias, and isotope proxies for salinity, such as $\delta^{13} \mathrm{C}$ in the basal plate in very large scales from tarpon, offers a unique opportunity to assess whether underplating bias precludes the use of interior increments for isotope ratio histories. Previous work on tarpon scales using discrete paired subsamples from interior and exterior increments of tarpon showed strong positive correlations between $\mathrm{Sr} / \mathrm{Ca}$ and $\delta^{13} \mathrm{C}$ values, reflecting simultaneous shifts in both proxies (Woodcock \& Walther 2014). These positive correlations were confirmed in the present study, and such patterns were expected given that both dissolved ambient water $\mathrm{Sr} / \mathrm{Ca}$ values and $\delta^{13} \mathrm{C}$ ratios of particulate organic and inorganic matter increase with salinity in most systems (Fry 2002, Kaldy et al. 2005, Walther \& Limburg 2012). For instance, in Texas freshwater, Sr/Ca endmembers are approximately $5.0 \mathrm{mmol} \mathrm{mol}^{-1}$ (Walther \& Nims 2015), which is $3.5 \mathrm{mmol} \mathrm{mol}^{-1}$ below the globally homogeneous marine endmember of $8.5 \mathrm{mmol} \mathrm{mol}^{-1}$ (de Villiers 1999) and provides sufficient resolution to detect movement across salinity gradients in calcified structures. In addition, $\delta^{13} \mathrm{C}$ values of particulate organic matter across San Antonio Bay increases from a freshwater endmember of $-29 \%$ to a marine endmember of $-21 \%$ (Bishop et al. 2017). As a result, the positive relationships between $\mathrm{Sr} / \mathrm{Ca}$ and $\delta^{13} \mathrm{C}$ values in scales suggest that both are valuable indicators of salinity history in tarpon, despite any underplating bias that 
might be reducing the absolute magnitude of change that would be seen in scale $\delta^{13} \mathrm{C}$ values in the absence of underplating. For this species, assays of interior scale increments appear to provide robust assessments of isotope-based salinity and dietary histories.

\section{Atlantic tarpon migrations}

Scale chemical transects in wild tarpon demonstrated substantial individual variability in oligohaline habitat use and confirmed that transhaline movements are not obligate but rather highly facultative for this species. The results presented in this work must be interpreted with caution given the relatively small sample size investigated (29 fish). However, even with this small sample size, this work demonstrated that movement patterns are highly variable among individuals and oligohaline residence is by no means uniform for this species. Although there has been consistent evidence that tarpon are found in fresh waters, direct quantification of the proportion of individuals using such habitats has rarely been estimated. Indeed, due to uncertainty about the facultative nature of freshwater habitat occupancy, this species has received a range of life history designations, including amphidromous, catadromous, and facultatively diadromous (reviewed by Rohtla \& Vetemaa 2016). Evidence for euryhaline movements and oligohaline residence has come from a variety of sampling methods. Much of the early work on tarpon distribution and larval development noted that juvenile tarpon are regularly captured with traps, cast nets, and seines in low-salinity environments in locations such as Indian River, Florida (Harrington 1958), Seadrift, Texas (Marwitz 1986), and Lake Nicaragua and the Chagres River in Panama (Breder 1944). More recently, Luo et al. (2008) obtained high-resolution satellite-based geospatial data from pop-up archival transmitting (PAT) tags and derived a method to use the wet-dry sensor to estimate salinity histories to match movement tracks. In a field trial using a $50 \mathrm{~kg}$ tagged tarpon, the tag recorded movements into the St. Lucie River on the Atlantic coast of Florida where the tarpon resided at salinities from 2 to 10 for 9 continuous days. These data agree with the findings of the scale chemistry assays that oligohaline residence is not restricted to early juvenile life history stages.

There have been a small number of efforts to characterize migratory histories of tarpon using geochemical markers. To our knowledge, only 2 studies have used otolith chemistry for tarpon. Brown \& Sev- erin (2007) analyzed otoliths from tarpon collected in Lake Nicaragua and the Rio San Juan in Nicaragua (4 fish from each location), as well as 4 fish from the southern coastal region of Texas, similar to this study. Using a wavelength-dispersive electron microprobe to obtain 2-dimensional maps and focus-to-edge transects of $\mathrm{Sr} / \mathrm{Ca}$, they found 2 distinct patterns. For the Nicaraguan fish, Sr/Ca patterns indicated spawning and early life rearing in marine waters followed by subsequent movement into oligohaline waters later in life. For the Texas fish, the opposite pattern was observed, with oligohaline residence dominant early in life and movement towards marine habitats later in life. Although this preliminary assessment involved only 4 fish per sampling region, it offered an intriguing glimpse into the individually and geographically variable habitat use patterns. More recently, Rohtla \& Vetemaa (2016) analyzed 37 otoliths from immature specimens obtained at a fish market in French Guiana and obtained Sr/Ca and $\mathrm{Ba} / \mathrm{Ca}$ transects across otoliths. They found that movements were highly variable among individuals, with some recruiting to brackish waters and others to marine waters, and variable transhaline movements subsequently. Unlike the results reported here and by Brown \& Severin (2007), Rohtla \& Vetemaa (2016) report that only $8 \%$ of sampled individuals used fresh water during their lives. This may be due to regional differences in propensity for movement into rivers, or perhaps the degree of oligohaline habitat suitability in different parts of the world. Because of this individual variability, Rohtla \& Vetemaa (2016) discourage the use of the terms catadromous or amphidromous and instead suggest the term 'euryhaline marine migrant' for tarpon. Our results support this conclusion, and note that caution must be taken when employing absolute life history designations in potentially facultative species (Secor \& Kerr 2009).

The work presented here is the culmination of ongoing efforts to determine the ability of scale chemistry to reveal migratory and dietary markers in tarpon. In the first assessment of the potential of this method, Woodcock \& Walther (2014) successfully used paired subsamples of increments across scales to retrieve both elemental and isotopic values from individual scales. Salinity histories (as indicated by Sr/Ca and $\delta^{13} \mathrm{C}$ ) from fish captured along the Texas coast and Puerto Rico were not consistent, suggesting individual variability in habitat residence. Dietary histories (as indicated by $\delta^{15} \mathrm{~N}$ ) generally indicated ontogenetic increases in trophic position, although edge values of scales from Puerto Rican fish were lower than expected, suggesting that movements into 
marine waters may have been accompanied by shifts in the isotopic baseline of $\delta^{15} \mathrm{~N}$ values. Subsequent to this work, Seeley et al. (2015) developed the crosssectional approach to obtain high-resolution $\mathrm{Sr} / \mathrm{Ca}$ histories, thereby opening the door for more robust assessments of transhaline movements in large scales. Further, Seeley et al. (2017) compared elemental and isotope ratio patterns across multiple scales from the same individual tarpon to determine consistency among scales. Patterns of both proxies were correlated and shifts were coincident among all nonregenerated scales in both wild fish and fish reared in captivity and constant salinity environments, indicating that scale choice would not bias interpretation of individual dietary and movement histories. Finally, the results here show the utility of applying scale chemistry proxies to reconstruct histories in wild fish.

A final insight provided by our scale chemistry analyses is variable dietary histories that accompanied migratory movements. Mobile fishes may participate in local food webs and thereby link disparate communities through predation and alter biodiversity, community stability, and energetic subsidies (Polis et al. 1997, Duffy et al. 2007). Alternatively, these immigrants may not rely heavily on local dietary items during transitory movements and therefore not provide significant food web linkages among habitats despite their presence. We found that $\delta^{15} \mathrm{~N}$ values in fish scales were tightly coupled to both $\mathrm{Sr} / \mathrm{Ca}$ and $\delta^{13} \mathrm{C}$ values, potentially suggesting that their diets shifted significantly when making migratory movements into different salinity regimes. Patterns in lifetime $\delta^{15} \mathrm{~N}$ values appeared to reflect changes in trophic position either with ontogeny or with movement between oligohaline and estuarine or marine waters. Baseline particulate organic matter $\delta^{15} \mathrm{~N}$ values in anthropogenically impacted Texas estuaries typically decrease with salinity by as much as $10-14 \%$ between freshwater and marine endmembers (Bishop et al. 2017). As a result, for tarpon that moved from fresh to marine waters, their scales would be expected to have inverse changes in $\delta^{15} \mathrm{~N}$ and $\delta^{13} \mathrm{C}$ values given their inverse relationship in baseline values of each isotope ratio with salinity. However, $\delta^{15} \mathrm{~N}$ values were positively related to both $\mathrm{Sr} / \mathrm{Ca}$ and $\delta^{13} \mathrm{C}$ values, implying that movements into oligohaline waters were accompanied by decreases in $\delta^{15} \mathrm{~N}$ values, opposite of the trend expected if scale $\delta^{15} \mathrm{~N}$ values were driven by local baseline $\delta^{15} \mathrm{~N}$ values alone. One potential explanation for this discrepancy is that tarpon feed at different trophic positions in either oligohaline or estuarine and marine waters. This explanation is plausible given that tarpon are highly opportunistic feeders and are known to target low trophic position dietary items when inhabiting oligohaline waters as juveniles, including copepods, aquatic insects, terrestrial insects, and fly larvae (Jud et al. 2011). Importantly, shifts in $\delta^{15} \mathrm{~N}$ values coincided with shifts in $\delta^{13} \mathrm{C}$ values regardless of whether those shifts occurred early or later in life, suggesting that tarpon shift diets to local food items, likely at different trophic levels, after a transhaline movement and therefore participate in local food webs. Tarpon are thus transient yet facultative predators that could have important yet currently unquantified effects on food web dynamics in oligohaline and freshwater environments.

This work demonstrates the broad potential of scales as alternatives to otoliths to provide important migration and dietary history information in migratory fishes. The coupled use of isotopic and elemental proxies yields novel information about individual variability and facultative habitat use in mobile predators. While the use of incremental subsampling is not necessarily transferrable to all taxa due to differences in scale size, we encourage continued exploration of the utility of scale chemistry in other species. Scale chemistry and other non-lethally sampled structures, such as fin rays, will be of particular utility for imperiled species that require detailed information about habitat requirements to develop spatially explicit management strategies that explicitly quantify the suite of habitats and rates of residency across life history stages. However, for imperiled species, mortality typically must be avoided and therefore otolith chemistry may be an impractical approach that necessitates the development of proxies in these alternative structures. The continued development and validation of isotopic and elemental proxies in scales is thus of great importance for conservation and management of vulnerable species.

Acknowledgements. The Saltwater Fisheries Enhancement Association, the Rotary Club of Corpus Christi Harvey Weil Sportsman Conservationist Award, and the Texas State Aquarium Wildlife Care, Conservation and Research Fund provided funding to B.D.W. for this project. Thanks to the Project Tarpon Tournament Series for donating scales and Marcus Poffenberger for providing opportunities to conduct fieldwork. Trace element analysis was conducted at Jackson School of Geosciences at the University of Texas at Austin with the help of N. Miller. Stable isotope analysis was conducted at the University of California Davis Stable Isotope Facility.

\section{LITERATURE CITED}

Adams AJ, Horodysky AZ, McBride RS, Guindon K and others (2014) Global conservation status and research needs 
for tarpons (Megalopidae), ladyfishes (Elopidae) and bonefishes (Albulidae). Fish Fish 15:280-311

Ault JS, Luo J (2013) A reliable game fish weight estimation model for Atlantic tarpon (Megalops atlanticus). Fish Res 139:110-117

Ault JS, Humston R, Larkin MF, Perusquia E and others (2008) Population dynamics and resource ecology of Atlantic tarpon and bonefish. In: Ault JS (ed) Biology and management of the world tarpon and bonefish fisheries. CRC Press, Boca Raton, FL, 217-258

Banner JL (2004) Radiogenic isotopes: systematics and applications to earth surface processes and chemical stratigraphy. Earth Sci Rev 65:141-194

Bégout ML, Bau F, Acou A, Acolas ML (2016) Methodologies for investigating diadromous fish movements: conventional, PIT, acoustic and radio tagging and tracking. In: Morais P, Daverat F (eds) An introduction to fish migration. CRC Press, Boca Raton, FL, 214-250

Bishop KA, McClelland JW, Dunton KH (2017) Freshwater contributions and nitrogen sources in a south Texas estuarine ecosystem: a time-integrated perspective from stable isotopic ratios in the eastern oyster (Crassostrea virginica). Estuaries Coasts 40:1314-1324

Bond MH, Miller JA, Quinn TP (2015) Beyond dichotomous life histories in partially migrating populations: cessation of anadromy in a long-lived fish. Ecology 96:1899-1910

* Borcherding J, Pickhardt C, Winter HV, Becker JS (2008) Migration history of North Sea houting (Coregonus oxyrinchus L.) caught in Lake IJsselmeer (The Netherlands) inferred from scale transects of ${ }^{88} \mathrm{Sr}:{ }^{44} \mathrm{Ca}$ ratios. Aquat Sci 70:47-56

Breder CM (1944) Materials for the study of the life history of Tarpon atlanticus. Zoologica 29:217-252

Brown RJ, Severin KP (2007) A preliminary otolith microchemical examination of the diadromous migrations of Atlantic tarpon Megalops atlanticus. In: Ault JS (ed) Biology and management of the world tarpon and bonefish fisheries. CRC Press, Boca Raton, FL, 259-274

Cambiè G, Kaiser MJ, Marriott AL, Fox J and others (2016) Stable isotope signatures reveal small-scale spatial separation in populations of European sea bass. Mar Ecol Prog Ser 546:213-223

Campana SE, Thorrold SR (2001) Otoliths, increments, and elements: keys to a comprehensive understanding of fish populations? Can J Fish Aquat Sci 58:30-38

* Chapman BB, Brönmark C, Nilsson JÅ, Hansson LA (2011) The ecology and evolution of partial migration. Oikos 120:1764-1775

Chapman BB, Skov C, Hulthén K, Brodersen J, Nilsson PA, Hansson LA, Brönmark C (2012) Partial migration in fishes: definitions, methodologies and taxonomic distribution. J Fish Biol 81:479-499

Clarke AD, Telmer KH, Shrimpton JM (2007) Elemental analysis of otoliths, fin rays and scales: a comparison of bony structures to provide population and life-history information for the Arctic grayling (Thymallus arcticus). Ecol Freshwat Fish 16:354-361

Courtemanche DA, Whoriskey FG, Bujold V, Curry RA (2006) Assessing anadromy of brook char (Salvelinus fontinalis) using scale microchemistry. Can J Fish Aquat Sci 63:995-1006

Crabtree RE, Cyr EC, Dean JM (1995) Age and growth of tarpon, Megalops atlanticus, from south Florida waters. Fish Bull 93:619-628

Crabtree RE, Cyr EC, Chaverri DC, McLarney WO, Dean
JM (1997) Reproduction of tarpon, Megalops atlanticus, from Florida and Costa Rican waters and notes on their age and growth. Bull Mar Sci 61:271-285

* de Villiers S (1999) Seawater strontium and Sr/Ca variability in the Atlantic and Pacific oceans. Earth Planet Sci Lett 171:623-634

Dingle H, Drake VA (2007) What is migration? Bioscience 57:113-121

* Duffy JE, Cardinale BJ, France KE, McIntyre PB, Thebault E, Loreau M (2007) The functional role of biodiversity in ecosystems: incorporating trophic complexity. Ecol Lett 10:522-538

* Dufour E, Höök TO, Patterson WP, Rutherford ES (2008) High-resolution isotope analysis of young alewife Alosa pseudoharengus otoliths: assessment of temporal resolution and reconstruction of habitat occupancy and thermal history. J Fish Biol 73:2434-2451

Elsdon TS, Wells BK, Campana SE, Gillanders BM and others (2008) Otolith chemistry to describe movements and life-history parameters of fishes: hypotheses, assumptions, limitations and inferences. Oceanogr Mar Biol Annu Rev 46:297-330

* Flem B, Moen V, Grimstvedt A (2005) Trace element analysis of scales from four populations of Norwegian Atlantic salmon (Salmo salar L.) for stock identification using laser ablation inductively coupled plasma mass spectrometry. Appl Spectrosc 59:245-251

Fowler AJ, Campana SE, Jones CM, Thorrold SR (1995) Experimental assessment of the effect of temperature and salinity on elemental composition of otoliths using laser ablation ICPMS. Can J Fish Aquat Sci 52:1431-1441

Fry B (2002) Conservative mixing of stable isotopes across estuarine salinity gradients: a conceptual framework for monitoring watershed influences on downstream fisheries production. Estuaries 25:264-271

*Harrington RW (1958) Morphometry and ecology of small tarpon, Megalops atlantica Valenciennes from transitional stage through onset of scale formation. Copeia 1958:1-10

Hobson KA (1999) Tracing origins and migration of wildlife using stable isotopes: a review. Oecologia 120:314-326

*KHolá M, Kalvoda J, Nováková H, Škoda R, Kanický V (2011) Possibilities of LA-ICP-MS technique for the spatial elemental analysis of the recent fish scales: line scan vs. depth profiling. Appl Surf Sci 257:1932-1940

*Hutchinson JJ, Trueman CN (2006) Stable isotope analyses of collagen in fish scales: limitations set by scale architecture. J Fish Biol 69:1874-1880

Johnson SP, Schindler DE (2012) Four decades of foraging history: stock-specific variation in the carbon and nitrogen stable isotope signatures of Alaskan sockeye salmon. Mar Ecol Prog Ser 460:155-167

Jud Z, Layman C, Shenker J (2011) Diet of age-0 tarpon (Megalops atlanticus) in anthropogenically-modified and natural nursery habitats along the Indian River Lagoon, Florida. Environ Biol Fishes 90:223-233

Kaldy JE, Cifuentes LA, Brock D (2005) Using stable isotope analyses to assess carbon dynamics in a shallow subtropical estuary. Estuaries 28:86-95

K Kerr LA, Cadrin SX, Secor DH (2010) The role of spatial dynamics in the stability, resilience, and productivity of an estuarine fish population. Ecol Appl 20:497-507

*Luo JG, Ault JS, Larkin MF, Barbieri LR (2008) Salinity measurements from pop-up archival transmitting (PAT) tags and their application to geolocation estimation for 
Atlantic tarpon. Mar Ecol Prog Ser 357:101-109

MacKenzie KM, Palmer MR, Moore A, Ibbotson AT, Beaumont WRC, Poulter DJS, Trueman CN (2011) Locations of marine animals revealed by carbon isotopes. Sci Rep 1:21

Marwitz SR (1986) Young tarpon in a roadside ditch near Matagorda Bay in Calhoun County, Texas. Management Data Series Number 100. Texas Parks and Wildlife Department Coastal Fisheries Branch, Austin, TX

Morse JW, Bender ML (1990) Partition coefficients in calcite: examination of factors influencing the validity of experimental results and their application to natural systems. Chem Geol 82:265-277

Perga ME, Gerdeaux D (2003) Using the $\delta^{13} \mathrm{C}$ and $\delta^{15} \mathrm{~N}$ of whitefish scales for retrospective ecological studies: changes in isotope signatures during the restoration of Lake Geneva, 1980-2001. J Fish Biol 63:1197-1207

* Polis GA, Anderson WB, Holt RD (1997) Toward an integration of landscape and food web ecology: the dynamics of spatially subsidized food webs. Annu Rev Ecol Syst 28: 289-316

Ramsay A, Milner N, Hughes R, McCarthy I (2012) Fish scale $\delta^{15} \mathrm{~N}$ and $\delta^{13} \mathrm{C}$ values provide biogeochemical tags of fish comparable in performance to element concentrations in scales and otoliths. Hydrobiologia 694:183-196

Ramsay AL, Hughes RN, Chenery SR, McCarthy ID (2015) Biogeochemical tags in fish: predicting spatial variations in strontium and manganese in Salmo trutta scales using stream water geochemistry. Can J Fish Aquat Sci 72: 422-433

Rodionov SN (2004) A sequential algorithm for testing climate regime shifts. Geophys Res Lett 31:L09204

* Rohtla M, Vetemaa M (2016) Otolith chemistry chimes in: migratory environmental histories of Atlantic tarpon (Megalops atlanticus) caught from offshore waters of French Guiana. Environ Biol Fishes 99:593-602

Schaefer K, Fuller D (2016) Methodologies for investigating oceanodromous fish movements: archival and pop-up satellite archival tags. In: Morais P, Daverat F (eds) An introduction to fish migration. CRC Press, Boca Raton, FL, p 251-289

Secor DH (1999) Specifying divergent migrations in the concept of stock: the contingent hypothesis. Fish Res 43:13-34

Secor DH, Kerr LA (2009) Lexicon of life cycle diversity in

Editorial responsibility: Stephen Wing,

Dunedin, New Zealand diadromous and other fishes. Am Fish Soc Symp 69: 537-556

Seeley M, Miller N, Walther B (2015) High resolution profiles of elements in Atlantic tarpon (Megalops atlanticus) scales obtained via cross-sectioning and laser ablation ICP-MS: a literature survey and novel approach for scale analyses. Environ Biol Fishes 98:2223-2238

Seeley M, Logan WK, Walther B (2017) Consistency of elemental and isotope-ratio patterns across multiple scales from individual fish. J Fish Biol 91:928-946

Terrill SB, Able KP (1988) Bird migration terminology. Auk 105:205-206

Trueman CN, Moore A (2007) Use of the stable isotope composition of fish scales for monitoring aquatic ecosystems. In: Dawson TE, Siegwolf RTW (eds) Stable isotopes as indicators of ecological change. Academic Press, Burlington, VT

* Tzadik OE, Curtis JS, Granneman JE, Kurth BN and others (2017) Chemical archives in fishes beyond otoliths: a review on the use of other body parts as chronological recorders of microchemical constituents for expanding interpretations of environmental, ecological, and lifehistory changes. Limnol Oceanogr Methods 15:238-263

Walther BD, Limburg KE (2012) The use of otolith chemistry to characterize diadromous migrations. J Fish Biol 81: 796-825

*Walther B, Nims M (2015) Spatiotemporal variation of trace elements and stable isotopes in subtropical estuaries: I. Freshwater endmembers and mixing curves. Estuaries Coasts 38:754-768

Wells BK, Bath GE, Thorrold SR, Jones CM (2000) Incorporation of strontium, cadmium, and barium in juvenile spot (Leiostomus xanthurus) scales reflects water chemistry. Can J Fish Aquat Sci 57:2122-2129

* Wells BK, Thorrold SR, Jones CM (2003) Stability of elemental signatures in the scales of spawning weakfish, Cynoscion regalis. Can J Fish Aquat Sci 60:361-369

WWoodcock SH, Walther BD (2014) Trace elements and stable isotopes in Atlantic tarpon scales reveal movements across estuarine gradients. Fish Res 153:9-17

*Woodcock SH, Grieshaber CA, Walther BD (2013) Dietary transfer of enriched stable isotopes to mark otoliths, fin rays, and scales. Can J Fish Aquat Sci 70:1-4

Submitted: March 15, 2017; Accepted: June 7, 2017

Proofs received from author(s): August 7, 2017 